\title{
Sistema Nacional de Avaliação e Progresso da Educação Superior
}

\section{Uma nova sistemática de avaliação do ensino superior brasileiro}

\author{
ACS - Assessoria de Comunicação Social do Ministério da Educação
}

\section{A EVOLUÇÃo dA AVALIAÇÃo}

As universidades brasileiras dispõem de mecanismos de avaliação desde a década de 1980. A Universidade de Brasília criou seu próprio Centro de Avaliação Institucional - CAI, que desenvolveu ações até 1994. Destaca-se, a partir de 1991, o trabalho desenvolvido pela Comissão Interinstitucional Nacional de Avaliação do Ensino Médico - CINAEM, na avaliação dos cursos de Medicina. Nos anos 90, funcionou no MEC o Programa de Avaliação Institucional das Universidades Brasileiras - PAIUB, que teve forte presença em muitas universidades brasileiras até 1996, quando foi implantado, durante a gestão do Ministro Paulo Renato Souza, o Exame Nacional de Cursos - ENC, que ficou conhecido como Provão. A partir do ano seguinte, o MEC começou a implantar a Avaliação das Condições de Oferta, que depois se transformou em Avaliação das Condições de Ensino - ACE. O primeiro avalia os alunos, por meio de uma prova no final do curso, o outro avalia a organização didático-pedagógica, o corpo docente e as instalações dos cursos.

Esses dois instrumentos tiveram o mérito de disseminar no País a cultura da avaliação. No entanto, foram tratados separadamente e a avaliação ficou basicamente restrita ao primeiro. A visibilidade e a simplicidade das notas da prova feita pelos alunos ofuscaram o outro componente, bastante significativo, do sistema da avaliação, representado pela Avaliação das Condições de Ensino. Por terem sido tratados como instrumentos isolados, o ENC e a ACE deixaram de construir uma visão sistêmica da avaliação, que combinasse os resultados dos dois instrumentos: o chamado Provão e as Condições de Ensino.

Apesar da visão parcial e simplista de avaliação, a prova aplicada aos alunos passou a ser considerada pela sociedade como uma avaliação suficiente. Como conseqüência, instalou-se uma avaliação incompleta. O primeiro passo para uma nova geração na sistemática da avaliação do Ensino Superior parte dos dois instrumentos, atualmente isolados, para a construção de um sistema de avaliação, combinando o exame dos alunos e a avaliação dos professores da graduação, contida na ACE.

Para que a avaliação capte as características do ensino superior em toda a sua complexidade, serão acrescentados ao ENC e à ACE outros dois aspectos da atividade acadêmica: a capacidade institucional e a responsabilidade do curso para com a sociedade.

Finalmente, o novo sistema introduz um importante elemento na avaliação: os compromissos da instituição e do curso com a superação de seus problemas e limitações, para assegurar a qualidade do ensino superior.

Essas são as bases da avaliação do ensino superior que será realizada a partir de agora. Uma avaliação mais completa, rigorosa e conseqüente, que aperfeiçoa, amplia e combina os instrumentos utilizados atualmente, transformando-os em um Sistema Nacional de Avaliação e Progresso da Educação Superior, apoiado em quatro pilares:

- o processo de ensino;

- o processo de aprendizagem;

- a capacidade institucional;

- a responsabilidade do curso com a sociedade em geral.

Para cada um desses itens será construído um indicador parcial; combinados, esses quatro indicadores comporão um Índice do Desenvolvimento do Ensino Superior - IDES.

Além disso, um Protocolo de Compromissos, a ser cumprido pela direção do curso e da instituição, visando à superação das falhas, insuficiências e dificuldades identificadas, fará parte do relatório final de avaliação.

\section{O CONTEÚdO DA AVALIAÇÃo}

\subsection{Avaliação do ensino}

A base da avaliação do processo de ensino será o conjunto de informações relativas ao corpo docente, contidas na Avaliação das Condições de Ensino. 
Para a construção de um Indicador de Ensino, serão realizados os seguintes ajustes ao sistema atual:

i. Serão utilizadas informações relacionadas ao corpo docente dedicado à graduação, relativas a:

- número e formação;

- dedicação às atividades docentes;

- publicações e outros trabalhos;

- avaliações de docentes feitas por alunos, quando houver.

i. Os demais dados da Avaliação das Condições de Ensino serão tratados separadamente, para a avaliação da capacidade institucional.

iii. Os dados que compõem essa avaliação serão reunidos e divulgados na Internet, em uma Plataforma da Graduação a ser criada para esse fim.

\subsection{Avaliação da aprendizagem}

O Indicador de Aprendizagem será baseado na nota dos alunos do curso, partindo dos seguintes ajustes ao antigo Exame Nacional de Cursos:

i. No lugar de apenas uma prova, no final do curso, o Exame Nacional de Desempenho do Corpo Discente prevê a aplicação de duas, uma no final do primeiro ano, outra no final do último ano do curso. Isso permitirá, por um lado, localizar de maneira mais precisa onde se situam as dificuldades e qualidades do curso; por outro lado, a comparação entre a primeira e a segunda prova mostrará o avanço realizado pelo aluno graças exclusivamente ao curso que segue, independentemente da formação recebida antes da sua aprovação para o curso superior.

i. As provas não se limitarão a aferir a fixação de conteúdos programáticos, ministrados nos cursos. Elas avaliarão também a capacidade do aluno de se ajustar às novas exigências, decorrentes da rápida evolução do conhecimento nos anos seguintes à sua formatura, e sua aptidão para compreender temas exteriores ao âmbito de sua profissão, ligados à realidade brasileira e mundial e a outras áreas do conhecimento. Para tanto, haverá um balanceamento no conteúdo das verificações: $70 \%$ da nota obtida serão relativos aos conteúdos programáticos do curso, e $30 \%$ a outros conhecimentos, próprios da formação geral de um universitário.

iii. O Exame Nacional de Desempenho do Corpo Discente será dirigido a todos os cursos oferecido por Instituições de Ensino Superior brasileiras.

iv. A critério da Comissão Nacional de Orientação da Avaliação, sendo tecnicamente confiável, po- derão ser usadas amostras aleatórias de alunos, uma vez que o objeto da avaliação é o curso, não o aluno. O uso da amostragem também reflete uma busca de eficiência e redução de custos, levando-se em conta que logo chegaremos a seis milhões de alunos. Obviamente, sempre que o número de alunos de um curso for tão pequeno que não permita o desenho de uma amostra representativa, a prova será aplicada a todos eles. Os alunos que não forem selecionados para a amostra mas desejarem realizar a prova, para curriculum ou avaliação própria, poderão fazê-lo. Entretanto, sua nota não será levada em consideração para a avaliação do curso.

v. A construção dos instrumentos do Exame Nacional de Desempenho do Corpo Discente (prova e questionários aos alunos e coordenadores de curso) seguirá princípios rígidos de consistência, pertinência e validade.

\subsection{Avaliação da capacidade institucional}

A avaliação dos processos de ensino e aprendizagem não basta para captar a complexidade de uma instituição e seus cursos. A avaliação completa exige informações e análises sobre o conjunto da instituição e de cada curso. Para tanto, uma avaliação institucional levará em conta, entre outros aspectos:

- a oferta de programas de pós-graduação;

- a produção e divulgação científicas;

- as instalações de laboratórios;

- as instalações físicas;

- o plano de cargos e salários;

- o acervo bibliográfico;

- os métodos pedagógicos usados.

Para a avaliação da capacidade institucional, serão utilizados os dados específicos da ACE. A critério da Comissão Nacional de Orientação da Avaliação, informações adicionais poderão ser incluídas posteriormente ao sistema de avaliação.

Essas informações servirão de base para a construção de um Indicador de Capacidade Institucional.

\subsection{Avaliação da responsabilidade}

Uma das principais críticas da sociedade às instituições de ensino superior e seus cursos é o fato de atuarem sem o necessário envolvimento com a realidade do mundo, do país e de sua localidade, sem atender à demanda por profissionais no setor público e privado; suas pesquisas não dariam resposta aos problemas da população, da indústria, do governo; seu ensino não formaria o profissional adaptado às necessidades do presente e do futuro. Para corrigir 
isso, será instituído um indicador para aferir a contribuição dos cursos das instituições de ensino superior à sociedade, por meio de seu desenvolvimento social, verificando:

a) o conteúdo dos cursos nas áreas voltadas à solução de problemas nacionais, como engenharias, saúde, arquitetura, pedagogia;

b) o curriculum dos cursos e sua contribuição para a solução dos problemas da sociedade brasileira, especialmente mediante o uso de programas de residência médica e serviços civis em geral;

c) o envolvimento dos cursos com o setor industrial, a agricultura, os serviços da iniciativa privada;

d) a existência de programas de ensino a distância para a graduação;

e) o uso de instrumentos e ações afirmativas para corrigir discriminações sociais, raciais, de gênero ou contra pessoas com necessidades especiais;

f) a ênfase em programas de formação de professores para o ensino básico;

g) a orientação dos cursos à demanda local;

h) a existência de atividades qualificadas de extensão universitária, mesmo não exclusivamente vinculadas ao curso em questão;

i) a integração entre as atividades de extensão e as de ensino (disciplinas da grade curricular) e pesquisa (trabalhos de fim de curso ou projetos de iniciação científica), desenvolvidas no âmbito do curso ou de caráter multidisciplinar;

j) a existência de foco das atividades de extensão sobre prioridades de interesse social, principalmente no setor educacional;

k) o nível de participação efetiva e de contribuição relativa de estudantes, professores e pessoal técnico-administrativo do curso em questão, no âmbito das atividades de extensão avaliadas;

I) os padrões de eficiência e eficácia do modelo de gestão dessas atividades, assim como a democratização e efetiva participação da comunidade acadêmica na definição de propósitos e na administração da instituição.

Com base nessas informações, será criado um Indicador de Responsabilidade. A introdução desse novo indicador nos parâmetros de avaliação do MEC baseia-se em duas convicções: primeiro, de que é desejável, para a formação do universitário, que ele tenha experiência em atividades relacionadas a intervenções de interesse social; segundo, de que é preciso, para a sustentabilidade do sistema universitário, que haja uma contribuição significativa das
Instituições de Ensino Superior para a inclusão social, o desenvolvimento econômico-social e o desenvolvimento científico e tecnológico.

\subsection{0 protocolo de compromissos para o progresso do curso e da instituição}

No novo sistema, o processo de avaliação não se limitará a medir o desempenho da instituição - ensino, aprendizagem, capacidade institucional, responsabilidade. Fará também parte da avaliação um conjunto de compromissos da instituição e do curso, para:

- superar suas dificuldades;

- aprimorar suas atividades;

- melhorar seu desempenho;

- expandir sua contribuição para com a sociedade;

- contratar, formar e melhor remunerar seu pessoal;

- melhorar suas instalações físicas e laboratórios;

- ampliar seu acervo bibliográfico.

\subsection{O Índice do Desenvolvimento do Ensino Superior}

Com base nos quatro indicadores parciais - de ensino, de aprendizagem, de capacidade institucional e de responsabilidade - será calculado um Índice do Desenvolvimento do Ensino Superior - IDES e atribuído a cada curso e cada instituição. Diferente da limitada medição de aprendizado apenas, o novo indicador será capaz de captar todas as dimensões e complexidades do sistema universitário.

A construção do IDES não apresenta qualquer dificuldade, na opinião de estatísticos que participaram da elaboração e da análise de índices similares, como o IDH (Índice de Desenvolvimento Humano). O Índice do Desenvolvimento do Ensino Superior é um salto de qualidade na avaliação realizada até aqui, e por isso será utilizado pelo MEC em suas análises, classificações e medidas regulatórias, que incluem o credenciamento e o descredenciamento de cursos e instituições. Ao divulgar todas as informações de forma transparente (salvo a privacidade de cada aluno e professor), o MEC oferecerá condições, àqueles que assim desejarem, de limitarem sua avaliação ao exame aplicado aos alunos, como já acontecia com a nota do ENC, mesmo sabendo que essa avaliação não aproveita toda a riqueza do novo sistema.

\section{A CLASSIFICAÇÃO DE INSTITUIÇÕES E CURSOS}

Com base no Índice do Desenvolvimento do Ensino Superior, o MEC classificará os cursos de maneira a responder às necessidades de candidatos, 
alunos, pais, professores, da sociedade em geral e do próprio Governo, responsável por regular e ajustar o ensino superior às prioridades nacionais. À CONAV caberá definir a fórmula que combinará os quatro indicadores parciais que comporão o Índice (ensino, aprendizagem, capacidade institucional e responsabilidade com a sociedade).

Em um país com as diversidades do Brasil, com centenas de instituições recém-criadas, cuja simples existência, em alguns casos, já implica em avanço cultural e benefício aos jovens da região, não se justifica classificar todos os cursos e instituições em um único bloco. Novos cursos em municípios pequenos não devem ser classificados no mesmo bloco que instituições quase centenárias das grandes cidades. Assim, eles serão classificados por Região, Estado, pelo número de habitantes da cidade onde se localizam, pelo tempo desde a fundação e o credenciamento.

A divulgação de todos os dados com total transparência permitirá, no entanto, que uma classificação única seja feita por interessados e curiosos. O novo sistema permitirá ainda que cada pessoa ou instituição dê prioridade a qualquer um dos quatro indicadores, fazendo sua classificação de acordo com os aspectos que mais valorize.

Para evitar prejuízo ou benefício de um ou outro curso por causa de diferenças insignificantes, com base em décimos de pontos, a classificação será apresentada em blocos de cursos: bem avaliados, intermediários e não satisfatórios. Em casos especiais, a Comissão Nacional de Orientação da Avaliação poderá destacar instituições com desempenho excepcionalmente bom ou com péssimo nível de desempenho.

\section{A DIVULGAÇÃo do RELATÓRIO}

O Relatório de Avaliação e Progresso será divulgado a toda a sociedade. Ao MEC caberá:

i. apresentar uma análise comparativa dos cursos, usando as informações do relatório, e

ii. zelar pelo cumprimento do Protocolo de Compromissos para o Progresso.

\section{O ÓRGÃO AVALIADOR}

A avaliação será conduzida por uma Comissão Nacional de Avaliação e Progresso do Ensino Superior - CONAPES, formada por membros da Diretoria de Estatísticas e Avaliação da Educação Superior do Instituto Nacional de Estudos e Pesquisas Educacionais Anísio Teixeira - INEP, e da Diretoria de Supervisão do Ensino Superior da Secretaria de
Educação Superior, nomeada pelo Ministro da Educação e respondendo diretamente ao seu Gabinete.

Para fiscalizar as atividades de avaliação e fornecer o suporte acadêmico necessário, será criada uma Comissão Nacional de Orientação da Avaliação CONAV, com membros escolhidos entre personalidades indicadas pela sociedade civil e entidades representativas da academia, com mandato de três anos, nos moldes do Conselho Técnico e Científico da CAPES. Além disso, cada instituição de ensino superior e cada curso devem constituir uma Comissão Própria de Avaliação - CPA, contando necessariamente com a participação de seus três segmentos (docentes, discentes e pessoal administrativo) e de representantes da sociedade.

\section{OS PASSOS DA AVALIAÇÃO}

A CONAPES procederá à avaliação seguindo um procedimento de oito passos, que se inicia com o preenchimento de formulário-padrão eletrônico, disponível e enviado pela Internet, e se encerra com a apresentação de um Relatório de Avaliação e Progresso para cada curso, conforme os passos a seguir (órgão - ação):

1. CONAPES anuncia o início do processo de avaliação, colocando à disposição das Instituições de Ensino Superior, por meio de plataforma a ser criada para esse fim, um formulário-padrão, para ser preenchido por cada instituição e curso, para a realização da avaliação do ensino, da capacidade institucional e a análise da responsabilidade para com a comunidade.

2. Instituição avaliada distribui o formulário-padrão a todos os seus cursos, que seguem a mesma rotina, juntamente com a sua CPA. Sob a coordenação da sua CPA, com a participação obrigatória dos três segmentos (docentes, discentes e pessoal administrativo), sistematiza as informações solicitadas sobre o corpo docente, a capacidade institucional e a responsabilidade social.

3. Instituição avaliada envia à CONAPES o formulário-padrão preenchido com o resultado de seu auto-conhecimento, e o divulga a toda a comunidade.

4. CONAPES aplica o exame de aprendizado do corpo discente.

5. CONAPES elabora um relatório preliminar, que inclui a avaliação de ensino, a avaliação de aprendizagem, a avaliação da capacidade institucional e a análise da responsabilidade e o envia à Instituição avaliada; esse relatório conterá os 
quatro indicadores e o Índice do Desenvolvimento do Ensino Superior de cada curso; e define os termos e as exigências para o Protocolo de Compromissos para o Progresso do curso.

6. Instituição avaliada analisa o relatório preliminar, com a participação dos três segmentos, aprovando ou contestando seus termos, e define seus compromissos visando à superação das dificuldades e ao progresso nas funções acadêmicas, preparando o Protocolo de Compromissos, e o envia ao MEC.

7. CONAPES elabora, com o auxílio de consultores ad hoc, o relatório final de avaliação e progresso, para imediata e ampla divulgação, contendo o Protocolo de Compromissos a ser seguido pela Instituição avaliada, nos anos seguintes, para alcançar seu progresso.

8. Instituição avaliada divulga o relatório final à sua comunidade, para conhecimento, análise e confirmação.

Serão criados instrumentos para sistematizar as informações referentes aos processos descritos acima. Toda essa informação (exceto a nota de cada aluno, pois sua individualidade será preservada) estará disponível para consulta pública, em plataforma eletrônica a ser criada para esse fim.

Esse processo será aplicado a cada três anos a cada curso, a menos que as condições apontem para a necessidade de uma avaliação anual ou bienal. Anualmente, serão escolhidas determinadas áreas do conhecimento para serem avaliadas, devendo o processo ser aplicado a todos os seus cursos. Em 2004, será aplicado o exame aos alunos de ciências da saúde, ciências biológicas e educação. Em 2005, serão avaliados os alunos de ciências exatas e da terra, engenharias e ciências agrárias. Em 2006, o processo será aplicado aos alunos das áreas de ciências humanas, exceto educação, ciências sociais aplicadas, lingüísticas, letras e artes.

Além desse processo, aplicado a todos os cursos e instituições a cada três anos, a CONAPES apontará alguns cursos e instituições para análise mais rigorosa e direta, por meio de visitas. Essas instituições serão objeto de uma aferição fina e serão escolhidas por três critérios - sorteio, adesão voluntária ou escolha direta por parte da CONAPES ou da CONAV, em função de suspeitas, denúncias ou reclamações. Caso sejam constatadas informações falsas, a instituição avaliada será objeto das sanções previstas na regulação do sistema, que podem incluir seu descredenciamento.

O resultado da primeira avaliação do novo siste- ma, na forma do Índice do Desenvolvimento do Ensino Superior, será anunciado até a última semana de outubro.

\section{AS CONSEQÜÊNCIAS DO RELATÓRIO}

A principal conseqüência do Relatório Final de Avaliação e Progresso será a indução da melhoria da qualidade dos cursos superiores, em função do conhecimento do Índice, dos indicadores parciais, da classificação dos cursos e do Protocolo de Compromissos. Tal melhoria se dará não mais como uma reação do mercado à nota de uma prova, mas sobretudo porque o Índice do Desenvolvimento do Ensino Superior subsidiará a função regulatória do poder público.

Caso um curso deixe de cumprir, no prazo determinado, as ações previstas em seu Protocolo de Compromissos, a CONAPES poderá recomendar ao MEC, agora com total justificativa, a suspensão de seu credenciamento. Da mesma forma, se não for possível sequer definir um Protocolo de Compromissos, em função das más condições do curso, ou caso a CONAPES não veja possibilidade de melhoria, a mesma decisão poderá ser tomada.

\section{ATORES DO PROCESSO dE AVALIAÇÃO}

INEP - Instituto Nacional de Estudos e Pesquisas Educacionais Anísio Teixeira.

SESU - Secretaria de Educação Superior do MEC. CONAPES (Comissão Nacional de Avaliação e Progresso do Ensino Superior, formada por membros da Diretoria de Estatísticas e Avaliação da Educação Superior do INEP, e da Diretoria de Supervisão do Ensino Superior da SESU) - nomeada pelo Ministro e diretamente ligada a ele, conduz a avaliação.

CONAV (Comissão Nacional de Orientação da Avaliação, nomeada pelo Ministro entre personalidades indicadas por entidades representativas da sociedade civil e da academia, professores, alunos e servidores, com mandato de três anos) - fiscaliza as atividades de avaliação, define o algoritmo que comporá o IDES, cria ou modifica instrumentos necessários ao funcionamento do sistema, fornece o suporte acadêmico necessário.

CPA (Comissão Própria de Avaliação de cada curso e instituição, formada por membros dos três segmentos - corpo docente, corpo discente e pessoal técnico-administrativo, além de representantes da sociedade) - preenche todas as informações solicitadas pela CONAPES, acompanha o auto-conhecimento e a preparação do Protocolo de Compromissos e a divulgação dos resultados à sociedade, 
garantindo a transparência do processo.

Aluno - realiza o Exame Nacional de Desempenho do Corpo Discente, participa, acompanha e fiscaliza o processo de avaliação, por meio da CPA, podendo cobrar da instituição e do curso a veracidade das informações prestadas e a realização das ações previstas no Protocolo de Compromissos.

Professor - participa da CPA, preenche o formulário de registro de atividades docentes, podendo cobrar da instituição e do curso a veracidade das in- formações prestadas e a realização das ações previstas no Protocolo de Compromissos.

Pessoal técnico-administrativo - participa, acompanha e fiscaliza o processo de avaliação, por meio da CPA, podendo cobrar da instituição e do curso a veracidade das informações prestadas e a realização das ações previstas no Protocolo de Compromissos.

\section{PUBLIQUE SEU ARTIGO NA REVISTA DA ABENO!}

Envie seu artigo!

Veja as normas

para a submissão

de originais na

página 94.
A

Revista da ABENO -

Associação Brasileira de Ensino Odontológico - tem como missão primordial contribuir para a obtenção de indicadores de qualidade do ensino odontológico respeitando os desejos de formação discente e capacitação docente, com vistas a assegurar o contínuo progresso da formação profissional e produzir benefícios diretamente voltados para a coletividade. Visa também produzir junto aos especialistas a reflexão e análise crítica dos assuntos da área em nível local, regional, nacional e internacional. 